\title{
Speeding up necropsy histology reports in a teaching hospital
}

\author{
E W Benbow, J C Howard
}

\begin{abstract}
A programme of repeated personal reminders substantially reduced the delay in producing final histological reports for necropsy cases. The proportion delayed for over four weeks was reduced from $69.7 \%$ to $46.7 \%$, and the proportion delayed for over 10 weeks was reduced from $38 \cdot 6 \%$ to $11 \cdot 7 \%$. This improvement may contribute to halting and reversing the now established trend in the decline of necropsy rates.
\end{abstract}

(f Clin Pathol 1993;46:567-568)

There has been a gradual decline in the numbers of necropsies over several decades. ${ }^{1-4}$ Of the many factors implicated in this, the delay between the original necropsy and the provision of a histological report and a final summary is thought to be important. Histology technicians may ascribe a low priority to preparing sections from necropsy material; many pathologists report necropsy histology with little enthusiasm; and there may be little urgency in the typing and distribution of final reports. ${ }^{56}$ In our department, sectioning and typing are generally carried out quickly, but even so, there have been unacceptable delays because of pathologists' tardiness in examining the slides and writing the final reports.

We describe a simple scheme of repeated personal reminders which has made a considerable difference to the department's aggregate performance.

Department of

Pathological Sciences

Stopford Building

University of

Manchester, Oxford

Road, Manchester

M13 9PT

E W Benbow

J C Howard

Correspondence to:

Dr Benbow

Accepted for publication

18 December 1992

\section{Methods}

At the beginning of 1991, the department formulated a policy whereby necropsy histology should be completed within four weeks of the original necropsy for non-neuropathological post mortem examinations, and within three months for neuropathological necropsies. At intervals of two weeks, apart from occasional exceptions because of annual leave or illness, all outstanding reports are examined, and a note is made of all those delayed for longer than the criteria in the policy statement. Each pathologist responsible for one or more outstanding reports is sent a personal letter which includes a list of the necropsies and a reminder of the criterion. The letters are generated with a word processor, and each batch of letters is saved and used as a template for the successive batch so that the amount of typing required is minimal, requiring typically between 5 and 10 minutes each fortnight for an amateur typist. Copies of the reminders are sent to the supervising consultant when necropsies carried out by junior staff become the subject of reminders.

For this study, the delay in completion of the final report for all necropsies carried out during 1988 and 1991 was calculated to the nearest whole week. Neuropathological necropsies were excluded. 1988 was chosen for comparison because the secretary primarily responsible for typing the necropsy reports was ill for a long period during 1989 and 1990.

\section{Results}

Non-neuropathological necropsies were carried out by 14 pathologists during 1988 and 18 pathologists during 1991 . The overall delays are shown in table 1 , which illustrates aggregated data for the whole department. Table 2 shows median delays for all six pathologists who carried out at least five necropsies in both 1988 and 1991.

The proportion of necropsies delayed for more than four weeks was reduced from $69.7 \%$ in 1988 to $46.7 \%$ in 1991 , and the proportion delayed for more than 10 weeks was reduced from $38.6 \%$ to $11 \cdot 7 \%$. Among the six pathologists who carried out a major number of necropsies in both study years, the performances were substantially improved in 1991 for each of the four individuals with poor performances in 1988.

Table 1 Numbers and cumulated proportions of histological reports completed after various periods of delay from original necropsy (whole department)

\begin{tabular}{llclc}
\hline $\begin{array}{l}\text { Number of weeks' } \\
\text { delay }\end{array}$ & $1988 n=$ & Cumulated \% & $1991 n=$ & Cumulated \% \\
\hline $1-2$ & 37 & $12 \cdot 6$ & 65 & $22 \cdot 3$ \\
$3-4$ & 52 & $30 \cdot 3$ & 90 & $53 \cdot 3$ \\
$5-6$ & 37 & $43 \cdot 0$ & 50 & $70 \cdot 4$ \\
$7-8$ & 25 & $51 \cdot 5$ & 35 & $82 \cdot 5$ \\
$9-10$ & 29 & $61 \cdot 4$ & 17 & $88 \cdot 3$ \\
$11-20$ & 59 & $81 \cdot 6$ & 24 & $96 \cdot 6$ \\
$21+$ & 54 & $100 \cdot 0$ & 10 & $100 \cdot 0$ \\
\hline
\end{tabular}

Table 2 Median delays from original necropsy to final histological report (selected pathologists)

\begin{tabular}{lcl}
\hline Pathologist & 1988 delay (weeks) & 1991 delay (weeks) \\
\hline 1 & 4 & $3 \cdot 5$ \\
2 & 31 & 8 \\
3 & 3 & 5 \\
4 & 31 & 5 \\
5 & 7 & 2 \\
6 & 11 & 4 \\
\hline
\end{tabular}




\section{Discussion}

Complete histological examination is regarded by many pathologists as an indication of a high quality necropsy, ${ }^{7}$ though a policy of selectivity has been advocated if this accelerates the generation of the final report. ${ }^{8}$ A recent study in this department showed that histology improves accuracy in a substantial proportion of necropsies, ${ }^{9}$ and we would support the recommendation that histology should be a routine and intrinsic part of every necropsy. ${ }^{10}$ Unfortunately, in a teaching hospital the competing claims of the biopsy and cytology services, together with teaching, research, and administration, may divert staff attention from diagnostic duties to which no particular urgency is attached. Similar workload pressures exist in district general hospitals.

Our reminder system is simple, cheap, and takes very little time. It is clear that several recipients of regular reminders are motivated to complete their cases before their reminders arrive; others prefer to use the reminders as cues to cases still to be completed. Because of this, the system has had greater success in reducing long term delays, but the overall performance has been greatly improved. Our criterion of four weeks was established before the Royal Colleges' Working Party made its recommendation that the delay should be no greater than three weeks, ${ }^{10}$ and it is possible that if we were to establish a more stringent criterion, then there would be a further improvement.
One of the potential benefits of reducing the delay before necropsy histology is complete is a reversal of the decline in our necropsy rates. ${ }^{4}$ Although it is too soon to draw any definitive conclusions, and assuming that the hospital clinicians took some time to become aware of the improvement, it is worth pointing out that the overall necropsy rate for 1992 so far is $39 \cdot 7 \%$, compared with $37 \cdot 1 \%$ for 1991 , suggesting that the improvement may have generated a more favourable clinical attitude to the necropsy. We would therefore commend our system to any teaching hospital wishing to improve and maintain the quality of its necropsy service.

We are grateful for Mrs Anita Brookes' assistance.

Waldron HA, Vickerstaff L. Necropsy rates in the United Birmingham Hospitals. $\mathrm{Br}$ Med $\mathcal{F} 1975$;ii:326-8.

2 Cameron HM, McGoogan E. Trends in hospital necropsy rates: Scotland 1961-74. Br Med f 1977;i:1577-80.

3 Friederici HH. Reflections on the postmortem audit. FAMA 1988;260:3461-5.

4 Start RD, Benbow EW. Transpennine necropsy rates: 1980-1991. ₹ Pathol 1992;168(Suppl): $146^{\AA}$.

5 Roberts WC. The autopsy. Its decline and a suggestion for its revival. $N$ Engl $¥ M$ Med 1978;299:332-8.

6 Saladino AJ, Dailey MC. The problem-orientated postmortem examination. Am f Clin Pathol 1978;69:253-7.

7 Anderson RE, Hill RB. Epitome. The current status of the autopsy in academic medical centers in the United
States. Am F Clin Pathol 1989;92(Suppl 1):s31-s7.

8 Hill RB, Anderson RE. The autopsy-medical practice and public policy. Stoneham, Massachusetts: Butterworths, 1988.

9 Hunt CR, Benbow EW, Knox WF, McMahon RFT, McWilliam LJ. Can pathologists diagnose bronchopneumonia? An audit of bronchopneumonia at necropsy. 7 Pathol 1992;168(Suppl):103A

10 Joint Working Party of the Royal College of Pathologists, the Royal College of Physicians of London and the Royal College of Surgeons of England. The autopsy and audit. London: Royal College of Pathologists, 1991. 